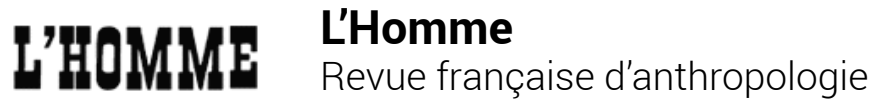

175-176 | juillet-septembre 2005

Vérités de la fiction

\section{Krishan Kumar. The Making of English National Identity}

Cambridge, Cambridge University Press, 2003, XIV +367 pages

Sylvie Lacombe

\section{(2) OpenEdition}

\section{Journals}

Édition électronique

URL : http://journals.openedition.org//homme/2076

DOI : 10.4000//homme.2076

ISSN : 1953-8103

Éditeur

Éditions de l'EHESS

Édition imprimée

Date de publication : 15 octobre 2005

Pagination : 555-557

ISBN : 2-7132-2035-1

ISSN : 0439-4216

Référence électronique

Sylvie Lacombe, «Krishan Kumar. The Making of English National Identity », L'Homme [En ligne],

175-176 | juillet-septembre 2005, mis en ligne le 30 novembre 2006, consulté le 24 septembre 2020.

URL : http://journals.openedition.org/lhomme/2076 ; DOI : https://doi.org/10.4000/lhomme.2076

Ce document a été généré automatiquement le 24 septembre 2020.

(c) École des hautes études en sciences sociales 


\title{
Krishan Kumar. The Making of English National Identity
}

Cambridge, Cambridge University Press, 2003, XIV +367 pages

\author{
Sylvie Lacombe
}

\section{RÉFÉRENCE}

Krishan Kumar, The Making of English National Identity, Cambridge, Cambridge University Press, 2003, XIV + 367 p., bibl., index.

1 QUI A NOTÉ, pour s'y perdre, la fréquente confusion entre Angleterre et Royaume-Uni, entre «anglais" et "britannique ", trouvera dans cet ouvrage érudit une réponse éclairante. Pour comprendre cette situation où la partie est prise (et se prend) pour le tout, Krishan Kumar retrace les grandes lignes du développement de la GrandeBretagne comme entité politique et culturelle. Sa thèse veut que l'identification de l'Angleterre avec une entité plus vaste qui l'englobe -Grande-Bretagne, Empire britannique - empêche le développement d'une identité étroitement nationale, tout en alimentant un nationalisme dit missionnaire qui met l'accent sur un projet civilisateur à accomplir. L'un des ressorts du livre est la réfutation des auteurs qui font de l'Angleterre, sinon le berceau du nationalisme et de l'État-nation, du moins l'un des premiers pays à avoir connu cette forme hybride. La démonstration et l'argumentation, convaincantes et rondement menées, sont un délice, les chapitres V et VI surtout.

2 La domination anglaise de la Grande-Bretagne, qui remonte à la conquête normande et à l'expansion anglo-normande, a été lente, non planifiée, progressant souvent à coup d'invitations locales: des lords gallois, irlandais ou écossais se tournant vers l'Angleterre pour assistance et soutien contre des ennemis locaux ou étrangers. Ainsi, l'incorporation du pays de Galles, à compter $\mathrm{du} \mathrm{XI} \mathrm{I}^{\mathrm{e}}$ siècle, peut-elle être dite complète et irréversible au début $\mathrm{du} \mathrm{XV}^{\mathrm{e}}$ siècle ; le royaume d'Irlande, dominé depuis le $\mathrm{XII}^{\mathrm{e}}$ siècle, est fusionné puis séparé sous Henri VIII, le roi d'Angleterre régnant alors sur les deux royaumes; et l'Écosse, marquée par une étroite intégration dès le $\mathrm{XI}^{\mathrm{e}}$ siècle, s'anglicise 
ensuite furtivement, mais sûrement. Ce premier travail impérialiste précise les contours de l'identité anglaise par contraste avec les Écossais «barbares», les "sauvages " Irlandais et les Gallois "fainéants ». Il faudra cependant un deuxième, voire un troisième, empire pour que se déploient toutes les possibilités que procurera une greffe de l'identité britannique.

3 L'expansion de l'empire au-delà des mers accélère l'émergence de la société britannique, car si les Anglais conduisent la chose, les peuples des autres fragments n'en jouent pas moins un rôle actif, parfois déterminant. Peu à peu l'identité britannique chapeaute celle des fragments, sans pour autant les effacer - sauf dans le cas anglais où la coïncidence sera presque parfaite. Le mouvement ne se fait pas sans recul toutefois. Au siècle d'Élisabeth, par exemple, un patriotisme centré sur la Couronne éclipse pour un temps l'idée britannique ; et la représentation de l'Angleterre en nation élue de Dieu se répand dans les sermons en chaire, dans les discours au parlement. Mais l'instabilité politique et la guerre civile, au XvII siècle, servent plutôt la construction de l'État britannique. Avec l'accession de James VI d'Écosse au trône en 1603, l'Angleterre devient partie prenante d'une monarchie à trois royaumes, dont le souverain se proclame roi de Grande-Bretagne, exigeant un nouveau drapeau, l'Union Jack. Son successeur, Charles II, poursuit l'œuvre d'intégration en faisant frapper Britannia sur les pièces de monnaie, une figure qui célèbre la Grande-Bretagne en héritière des gloires de Rome et de la Grèce antique. L'idée britannique se consolide aussi sur l'exclusion des catholiques : l'Acte de tolérance (1689) ne touche que les sectes dissidentes et les «papistes » resteront, même après l'acte qui les émancipe (1829), des traîtres potentiels. L'Acte d'union avec l'Écosse (1707) et l'incorporation de l'Irlande (1801) achèvent l'édification de l'État britannique, tandis que la révolution industrielle et son sous-produit, le mouvement travailliste, font de la Grande-Bretagne un système unifié. Mais la principale source d'intégration est sans contredit l'Empire; c'est lui qui soude ensemble les diverses parties de la Grande-Bretagne. Trait fondamental de leur culture, l'Empire est une force du bien dans le monde et, pour les Britanniques en général, propager la liberté, la civilisation et le christianisme signifie propager les lois et institutions anglaises. Tant et si bien que la puissance de l'Empire entérine la croyance qui fait des Anglais un peuple investi d'une mission divine le rendant supérieur. Sa contribution au monde est dite universelle, quand celle des autres peuples n'est que nationale.

Cette « conscience nationale " anglaise se cristallise au XIX siècle dans l'interprétation whig de l'histoire, un courant de pensée qui ratifie, quand il ne glorifie pas, le présent: les libertés anglaises y sont présentées comme une forme dynamique dont la croissance cumulative, continuelle et constante, s'élargit d'un précédent à l'autre. Une composante de ce mythe, l'anglo-saxonnisme, insiste cependant sur la race, la coutume et la culture au détriment des institutions étatiques, reléguant ainsi les Irlandais, les Gallois et bien des Écossais aux marges de l'héritage britannique. Cet accaparement du patrimoine commun a bien sûr son revers. Confondant Angleterre et Grande-Bretagne, les Anglais n'ont pas vu qu'il $\mathrm{y}$ a très peu d'institutions strictement anglaises: le Parlement, la monarchie, les cours de justice, le service civil, les forces armées, le système de diffusion (etc.), sont en effet des institutions toutes britanniques. Alors que les autres fragments « savent » qu'ils habitent un État multinational et lui réservent un attachement conscient, les Anglais restent indifférents à son égard parce qu'ils le tiennent pour acquis. Ils n'ont en conséquence pas vu venir, après la dissolution de l'Empire, la crise de l'État britannique. Les mesures de dévolution des pouvoirs en 
Écosse, au pays de Galles et en Irlande du Nord d'une part, et l'engagement de la Grande-Bretagne envers l'Union européenne d'autre part, signifient en effet une perte significative de la souveraineté parlementaire, pilier central de la constitution britannique. S'ajoutent à cela les pressions récentes des groupes minoritaires pour une représentation «multiculturelle » qui érodent, elles aussi, l'identité britannique. Ces faits somment les Anglais d'édifier une entité indépendante, soit précisément le contraire de ce qu'ils ont construit au cours des derniers siècles. Peu étonnant qu'ils trouvent l'expérience déconcertante!

5 En conclusion, ce livre passionnant montre comment chacune des îles britanniques doit son existence morale aux interactions qui la rattachent aux autres unités, comment l'ensemble ainsi formé modifie en retour leur existence respective et comment le tout est lui-même inséré dans une trame qui le déborde. S'interrogeant sur l'identité nationale anglaise, il s'avère ainsi une tentative fructueuse de comprendre le RoyaumeUni en tant que totalité sociale. 